\title{
Enhancing Urban Comprehensive Capacity for Urbanization Development: An Empirical Application of China's Southwest Ethnic Region
}

\author{
Linying Zhou, Yuanying Jiang* \\ College of Science, Guilin University of Technology, Guilin, China \\ Email: 102017863@glut.edu.cn, *jyy@glut.edu.cn
}

How to cite this paper: Zhou, L. Y., \& Jiang, Y. Y. (2019). Enhancing Urban Comprehensive Capacity for Urbanization Development: An Empirical Application of China's Southwest Ethnic Region. Current Urban Studies, 7, 247-264.

https://doi.org/10.4236/cus.2019.72012

Received: June 4, 2019

Accepted: June 24, 2019

Published: June 27, 2019

Copyright () 2019 by author(s) and Scientific Research Publishing Inc. This work is licensed under the Creative Commons Attribution International License (CC BY 4.0).

http://creativecommons.org/licenses/by/4.0/

(c) (i) Open Access

\begin{abstract}
We can say that enhancing the capacity and functionality of urbanization is the key to China's development. However, the urbanization development in various regions of China is unbalanced, especially in the southwestern ethnic region with relatively lagging behind the development. As a yardstick of urbanization development, urban comprehensive carrying capacity can provide a reference for urbanization development. Therefore, in order to promote the urbanization process in the southwestern ethnic region, this paper constructed an index system for measuring the urban comprehensive carrying capacity and used entropy method and coupling coordination degree model to calculate the urban comprehensive carrying capacity in China's southwest ethnic region in 2003-2016 and the coupling coordination between its elements. The results display that the overall carrying capacity of cities in the southwestern ethnic region shows an upward trend in 2003-2016: By analyzing the evolution of different elements, improving traffic and communication capacity significantly, population and environmental carrying capacity are relatively high; while the degree of coupling coordination of each element is not generally high, and the comprehensive carrying capacity and element coupling coordination degree of cities show that the spatial and temporal patterns are "double high" and "double low".
\end{abstract}

\section{Keywords}

China's Southwestern Ethnic Region, Urban Comprehensive Carrying Capacity, Coupling Coordination, Time and Space Differentiation

\section{Introduction}

Accelerating economic transformation and upgrading and accelerating socialist 
modernization are currently important issues, and urbanization is the key to China's development. However, in the central and western regions of China, especially in the southwestern ethnic region, due to the restrictive geographical conditions and weak economic development foundation, the urban development of the region is insufficient (Fang \& Zhang 2015). As a yardstick of urbanization development, urban comprehensive carrying capacity can provide a reference for urbanization development and promote urbanization. Therefore, in order to promote the urbanization process in the southwestern ethnic region, it is particularly important to scientifically and quantitatively evaluate the urban comprehensive carrying capacity.

In recent years, the term "integrated urban capacity" has frequently appeared in China's urban planning and urban development policies. Academic circles and government departments are paying more and more attention to the comprehensive carrying capacity of cities. The carrying capacity originated in ancient Greece (Hardin, 1976) and was originally applied in ecology. Malthus (1798) who put forward the "overpopulation theory" and "two series theory" in "Population Principles", found that resource and environmental constraints have an important impact on the growth process of human material. Verhulst (1838) not only expressed Malthus' population theory with Logistic mathematical formula, but also constructed a mathematical model of bearing capacity theory. Robert and Burgess (1921) first explicitly used the concept of carrying capacity, which they defined as "the highest limit of the number of individuals present under a particular environmental condition (mainly the combination of nutrients, living space, sunlight, etc.)".

After the 1940s, human society suffered from a series of crisis such as population expansion, natural resource shortage and environmental pollution. Research scholars began to apply the concept of carrying capacity to demography, resources, environmental science, economics, sociology and other fields (Dhondt, 1988; Seidl \& Tisdell, 1999; Clarke, 2002). Subsequent research on single factor carrying capacity for resources or the environment began to emerge. For example, resource carrying capacity refers to the population size under a certain material living standard that can be supported by a certain natural resource within a certain time and space. The definition of environmental carrying capacity evolved with the deeper understanding of this concept (Arrow et al., 1995). And they also systematically discussed the relationship between economic growth and economic quality and the carrying capacity of environmental economic activities for the first time, and believed that society should pay full attention to environmental carrying capacity. Professor Slather applied the system dynamics method to the ECCO model (ECCO model: Through the application of system dynamics method, considering the various factors affecting the land production potential, the bearing capacity of a certain area is regarded as a whole system, and the population capacity is dynamically calculated quantitatively), and con- 
sidered the population, environment, resources and social development as a whole, and simulated the dynamic process of population change and carrying capacity under several different policies (Oh, 1998).

The single factor carrying capacity only considers the role of the host's resources or environmental factors, and lacks the careful study of human activities and the overall consideration of the ecosystem, even some scholars (Daly, 1990; Ehrlich \& Wilson, 1991) proposed the society the concept of carrying capacity, but without in-depth study of the impact of social factors on resources or the environment, it is also difficult to draw conclusions that reflect the dynamic characteristics of development, and thus lack of comprehensive practical guidance.

Since the 1980s, the research scope of carrying capacity has been continuously broadened and deepened. Research on integrated carrying capacity is usually based on a basic assumption that if the regional development exceeds the threshold, it will cause irreversible damage to the environment (Kozlowski, 1990). Catton (1987) defines population carrying capacity as the maximum threshold for the environment to be stably carried. The threshold here is a function of population size, per capita consumption and waste production as explanatory variables. Oh et al. (2005) define that urban comprehensive carrying capacity refers to a state and comprehensive level of urban environment that can support population growth, human activities, land use, and dominant development without causing serious degradation and irreversible damage. Li and Zhao (2008) believe that the comprehensive urban carrying capacity refers to the threshold of the scale and intensity of human activities that can be carried by urban resources under certain conditions and certain social, economic and ecological environment. Gao et al. (2010) proposed that urban comprehensive carrying capacity refers to the ability of the city to carry out population and social and economic activities under the premise of no damaging impact on its resources, environment and science and education.

For different regions and different objects, scholars have done a lot of research by using different methods according to the research object. For example, Randolph (2004) pointed out that urban carrying capacity is a complex system. To know which elements of the system are on the threshold, it is necessary to measure the various elements in the system according to the actual situation of the area, and to circle the scientific threshold range. Hopton et al. (2010) proposed to apply the theory of green GDP to the measurement of urban comprehensive carrying capacity, and measured the intensity of comprehensive carrying capacity through methods such as ecological footprint. Gonzalez-Mejia et al. (2012) selected six major cities in the Ohio urban agglomeration as the research objects, used the Fisher Information Index to analyze the organizational dynamics of the region, and elaborated on the development of urban and regional issues. Tehrani and Makhdoum (2013) established the urban carrying capacity model and studied the carrying capacity of the urban agglomerations in Tehran province. It is concluded that $85 \%$ of the urban agglomerations have reached the 
carrying capacity threshold, and the water resources are loaded. Fu et al. (2014) based on the "pressure-state-response" PSR model, constructed a comprehensive urban carrying capacity evaluation system in Xinjiang, and compared the comprehensive carrying capacity of cities in Xinjiang. Zeng et al. (2015) used the comparative research method to measure and compare the top ten urban agglomerations in China. Mu et al. (2017) used the function model to calculate the comprehensive carrying capacity of cities in prefecture-level cities in China in 2015, and explored the spatial distribution characteristics of urban comprehensive carrying capacity by using exploratory spatial data analysis methods.

Comprehensive references have found that the existing literature mainly focuses on the study of hardware factors such as water, land and other single-element scarce resources and the ecological environment that is difficult to reverse once it is destroyed, and less research on software factors such as public service capabilities and cultural strength. The research objects are mostly a few urban agglomerations with relatively mature development and related research (Chen et al., 2013; Wang et al., 2018b), but there has not been a time-space study of the comprehensive urban carrying capacity of China's southwestern ethnic regions. In summary, this paper takes the southwestern ethnic area as the research object, and builds the urban comprehensive carrying capacity model and its elements coupling coordination degree model to evaluate the urban comprehensive carrying capacity level and the coupling and coordination level of the internal elements, and to explore the development characteristics of urban comprehensive carrying capacity and its coupling degree of coordination in southwestern ethnic region.

\section{Research Objects, Data, Indicator System and Methodology}

\subsection{Research Objects and Data Sources}

This paper takes the southwestern ethnic region of China as the research object, including Yunnan Province, Guizhou Province and Guangxi Zhuang Autonomous Region. Considering the availability of data, the study is mainly aimed at 26 prefecture-level cities under the jurisdiction of the three provinces. The list of specific cities is shown in Table 1. This paper selects the continuous time series data of 14 years from 2003 to 2016 to measure the comprehensive carrying capacity level and the coupling coordination degree of elements of each city in

Table 1. Cities included in the southwest ethnic regions.

\begin{tabular}{ll}
\hline $\begin{array}{l}\text { Southwestern } \\
\text { ethnic region }\end{array}$ & \multicolumn{1}{c}{ Included cities } \\
\hline Yunnan & Kunming, Gujing, Yuxi, Baoshan, Zhaotong, Lijiang, Puer, Lincang \\
Guizhou & Guiyang, Liupanshui, Zunyi, Anshun \\
Guangxi & $\begin{array}{l}\text { Nanning, Liuzhou, Guilin, Wuzhou, Beihai, Fangchenggang, Qinzhou, Guigang, } \\
\text { Yuyin, Baise, Hezhou, Bechi, Laibin, Chongzuo }\end{array}$ \\
\hline
\end{tabular}


southwestern ethnic region of China. In the comprehensive evaluation index system, all indicators are mainly derived from the China Urban Statistical Yearbook and the China Statistical Yearbook from 2004 to 2017. Some of the missing data are based on the relevant statistical yearbooks of the provinces at the same time or calculated. Since the dimensional, order of magnitude, and attributes of the data are different, the raw data needs to be normalized.

\subsection{Establishment of Indicator System}

Given these initial efforts, several scholars argue that urban comprehensive carrying capacity concepts lack well-rounded and adequate definitions (Tan et al., 2008; Sarma et al., 2012). Zhu et al. (2010) argue that non-harmonious and imbalanced relations among resources, ecology, population growth, and socio-economic activities may significantly hamper sustainable development. Urban comprehensive carrying capacity is not only related to the study of ecology or physical infrastructure, but also comprises analysis on economic, social, environmental, and institutional aspects and other science (Downs et al., 2008; Liu, 2011).

In this study, urban comprehensive carrying capacity refers to the limit of population growth, urban physical development, and socio-economic activities that can be perpetually supported by the urban supporting systems and they will not incur apparent degradation and irrevocable damage. Key indicators that determine the urban comprehensive carrying capacity of an urban area are grouped into six main urban comprehensive carrying capacity components, i.e., population, environmental, resource, economic, public service and traffic \& communication. Each element is set as a secondary indicator with 26 third-level indicators (see Table 2).

\subsection{Methodology}

\subsubsection{Entropy Method}

Entropy is an important concept in thermodynamics and a parameter derived from the second law of thermodynamics. Entropy was originally used in physics to measure the degree of chaos in the system. It was originally proposed in 1854 by Clausius and in 1923 the Chinese physicist Professor Hu Gangfu translated it into "entropy". Entropy was later used in information economics to measure uncertainty, the degree of disorder of events or the degree of dispersion of indicators. This paper uses the entropy method to determine the weight of indicators.

First use all the data to form the original matrix $X=\left(x_{i j}\right)_{m \times n}, i=1,2, \cdots, n$, $j=1,2, \cdots, m$ Where $m$ is the number of indicators and $n$ is the number of cities., represents the value of the $j$ th indicator of the $i$ th city.

The selected indicators include positive indicators and negative indicators, so all indicators need to be dimensionless. The dimensionless treatment formula is as follows:

$$
\begin{array}{cl}
\text { positive indicators: } & y_{i j}=\left(x_{i j}-x_{j \min }\right) /\left(x_{j \max }-x_{j \min }\right), \\
\text { negative indicators: } & y_{i j}=\left(x_{j \max }-x_{i j}\right) /\left(x_{j \max }-x_{j \min }\right),
\end{array}
$$


Table 2. Evaluation index system of urban comprehensive carrying capacity.

\begin{tabular}{|c|c|c|}
\hline $\begin{array}{l}\text { Secondary } \\
\text { indicators }\end{array}$ & Three-level indicator & $\begin{array}{l}\text { Indicator } \\
\text { attribute }\end{array}$ \\
\hline \multirow{3}{*}{ Population } & Population density (person per square kilometer) & - \\
\hline & Population growth rate $(\%)$ & - \\
\hline & $\begin{array}{l}\text { Proportion of employed persons in the secondary and tertiary } \\
\text { industries }(\%)\end{array}$ & + \\
\hline \multirow{3}{*}{ Environmental } & Green coverage rate of urban built-up areas (\%) & + \\
\hline & The ratio of sewage treated (\%) & + \\
\hline & Living garbage treatment rate (\%) & + \\
\hline \multirow{6}{*}{ Resources } & Per capita daily water consumption (L) & - \\
\hline & Per capita water supply $\left(\mathrm{m}^{3}\right)$ & + \\
\hline & Per capita construction land $\left(\mathrm{m}^{2}\right)$ & + \\
\hline & 10,000 yuan of land value $\left(\mathrm{m}^{3}\right)$ & - \\
\hline & Gas penetration rate $(\%)$ & + \\
\hline & Per capita electricity consumption $(\mathrm{KW} \cdot \mathrm{h})$ & - \\
\hline \multirow{4}{*}{ Economic } & Economic density (yuan $/ \mathrm{km}^{2}$ ) & + \\
\hline & Per capita GDP (yuan) & + \\
\hline & Tertiary industry GDP as a share of GDP (\%) & + \\
\hline & Average wage of employees on the job (yuan) & + \\
\hline \multirow{4}{*}{ Public Service } & $\begin{array}{l}\text { Primary and secondary school teachers bear average the } \\
\text { number of students (person) }\end{array}$ & - \\
\hline & Number of hospital beds per 10,000 persons (unit) & + \\
\hline & $\begin{array}{l}\text { Number of have access to public library books per } 10,000 \\
\text { persons (unit) }\end{array}$ & + \\
\hline & Number of bus per 10,000 persons (unit) & + \\
\hline \multirow{6}{*}{$\begin{array}{c}\text { Traffic \& } \\
\text { Communication }\end{array}$} & Total passenger traffic (ten thousand people) & + \\
\hline & Total freight (ten thousand tons) & + \\
\hline & Per-capita urban road areas $\left(\mathrm{m}^{2}\right)$ & + \\
\hline & Number of Internet per 10,000 persons (users) & + \\
\hline & Number of mobile phone users per 10,000 persons (users) & + \\
\hline & Number of fixed telephone users per 10,000 persons (users) & + \\
\hline
\end{tabular}

Note: “+” indicates a positive indicator; “-” indicates a negative indicator.

where $x_{j \max }$ represents the maximum value of the $j$-item indicator and $x_{j \min }$ represents the minimum value of the $j$-item indicator. $\left(y_{i j}\right)_{m \times n}$ is a matrix that is dimensionless.

The entropy method is used to calculate the index weights. First calculate the proportion of the $j$ th indicator of $i$ th city in this indicator: 


$$
p_{i j}=y_{i j} / \sum_{i=1}^{n} y_{i j}
$$

calculate the entropy of the $j$ th indicator: $e_{j}=-(1 / \ln m) \sum_{j=1}^{m}\left[p_{i j} \times \ln \left(p_{i j}\right)\right]$,

calculate the difference coefficient of the th indicator: $g_{j}=1-e_{j}$,

calculate the weighting element of the $f$ th indicator: $w_{j}=g_{j} / \sum g_{j}$.

\subsubsection{Urban Comprehensive Carrying Capacity Evaluation Model}

$$
g(U)=\sum_{j=1}^{m} y_{i j} w_{i j}
$$

Among them, $g(U)$ represents the level of urban comprehensive carrying capacity. The larger the $g(U)$ value, the greater the comprehensive carrying capacity of the city. Since the ideal value of the index after the data is dimensionless is 1 , the ideal urban comprehensive carrying capacity value is 1 . Based on the evaluation 5 criteria of Feng and Yang (2013) and the comprehensive consideration of the complexity and volatility in the process of urban development, the judgment criteria for urban comprehensive carrying capacity are set (Table 3).

\subsubsection{Coupling Coordination Model}

In order to objectively and scientifically judge the internal coordination between the six elements of urban comprehensive carrying capacity, this paper draws on the capacity coupling concept and the capacity coupling coefficient model in physics (Liu et al., 2005), which can obtain the coupling degree function of the coupled system, and then from the coupling. The perspective of degree measures the internal coordination between the six elements. The coupling degree function is expressed as:

$$
C_{t}=6\left\{\frac{g\left(U_{1 t}\right)+g\left(U_{2 t}\right)+g\left(U_{3 t}\right)+g\left(U_{4 t}\right)+g\left(U_{5 t}\right)+g\left(U_{6 t}\right)}{\prod\left[g\left(U_{i t}\right)+g\left(U_{j t}\right)\right]}\right\}^{1 / 6}
$$

among them, $i, j=1,2,3,4,5,6(i \neq j)$. $C_{t}$ represents the degree of coupling,

\begin{tabular}{|c|c|c|}
\hline $\begin{array}{l}\text { Urban comprehensive } \\
\text { carrying capacity }\end{array}$ & $\begin{array}{c}\text { Carrying } \\
\text { capacity status }\end{array}$ & Connotation description \\
\hline$<0.4$ & Serious overload $\left(S_{1}\right)$ & Traditional extensive \\
\hline $0.4-0.6$ & Overload $\left(\mathrm{S}_{2}\right)$ & $\begin{array}{l}\text { Carrier is not enough to support the benign } \\
\text { development of the city }\end{array}$ \\
\hline $0.6-0.8$ & Critical load $\left(\mathrm{S}_{3}\right)$ & Urban development is on the edge of carrying capacity \\
\hline $0.8-1$ & Suitable for load $\left(\mathrm{S}_{4}\right)$ & Sustainable urban development \\
\hline$>1$ & Fully loadable $\left(\mathrm{S}_{5}\right)$ & Urban development with welfare surplus \\
\hline
\end{tabular}
and the value is between $0-1$. The larger the $C_{t}$ value, the better the coupling

Table 3. Judgment standards for urban comprehensive carrying capacity. 
degree, indicating that the orderly coordination between the systems is closely related.

Coordination is a method to measure the relationship between systems or internal elements in the development process, and is a guarantee to maintain the sustainable development of the system. In order to better evaluate the coupling coordination degree between the six elements of urban comprehensive carrying capacity, the coupling coordination degree model is constructed under the principles of scientific, systematic, comprehensive and hierarchical:

$$
D_{t}=\sqrt[6]{C_{t} \times T_{t}}
$$

where $D_{t}$ represents the degree of coupling coordination and $T_{t}$ represents the comprehensive evaluation index, i.e.:

$$
C_{t}=6\left\{\frac{g\left(U_{1 t}\right)+g\left(U_{2 t}\right)+g\left(U_{3 t}\right)+g\left(U_{4 t}\right)+g\left(U_{5 t}\right)+g\left(U_{6 t}\right)}{\prod\left[g\left(U_{i t}\right)+g\left(U_{j t}\right)\right]}\right\}^{1 / 6}
$$

where $a, b, c, d, e$ and $f$ are undetermined coefficients. Since population, environment, resources, economy, public services, and traffic $\&$ communication are equally important to the level of urban comprehensive carrying capacity, take $a=b=c=d=e=f=1 / 6$. The larger the value of $D_{t}$, the higher the coupling coordination between the internal elements of the carrying capacity and the more coordinated development of the elements in the city. This paper refers to the evaluation criteria of the mean distribution function method used by Wang et al. (2018a) (see Table 4).

\section{Result}

\subsection{Analysis of Spatial and Temporal Differences of Urban Comprehensive Carrying Capacity in Southwest Ethnic Region}

According to the linear comprehensive evaluation model, the changes of urban

Table 4. Classification criteria for coupling coordination degree.

\begin{tabular}{ccll}
\hline Serial number & Interval & \multicolumn{1}{c}{ Coordination level } & Types \\
\hline 1 & $0.00-0.10$ & Extreme imbalance $\left(\mathrm{D}_{1}\right)$ & \\
2 & $0.11-0.20$ & Serious imbalance $\left(\mathrm{D}_{2}\right)$ & Loss of recession \\
3 & $0.21-0.30$ & Moderate imbalance $\left(\mathrm{D}_{3}\right)$ & \\
4 & $0.31-0.40$ & Mild disorder $\left(\mathrm{D}_{4}\right)$ & Transition \\
5 & $0.41-0.50$ & On the verge of disorder $\left(\mathrm{D}_{5}\right)$ & \\
6 & $0.51-0.60$ & Reluctant coordination $\left(\mathrm{D}_{6}\right)$ & \\
7 & $0.61-0.70$ & Primary coordination $\left(\mathrm{D}_{7}\right)$ & \\
8 & $0.71-0.80$ & Intermediate coordination $\left(\mathrm{D}_{8}\right)$ & Coordinated rise \\
9 & $0.81-0.90$ & Good coordination $\left(\mathrm{D}_{9}\right)$ & \\
10 & $0.90-1.00$ & Quality coordination $\left(\mathrm{D}_{10}\right)$ & \\
\hline
\end{tabular}


comprehensive carrying capacity in 26 cities in southwestern ethnic region from 2003 to 2016 were obtained (Figure 1 ).

From the overall perspective of Figure 1, in the 26 cities in the past 14 years, the overall urban carrying capacity is generally fluctuating, but the overall level is low, most cities are critically loadable. According to the realistic judgment standard of the urban comprehensive carrying capacity of Table 2, the comprehensive carrying capacity level of 26 cities in the southwestern ethnic region can be divided into three stages: the first stage is 2003-2008, most of the cities are overloaded, only a small number of cities are in a critically loadable state; the second stage is 2009-2012, the city's comprehensive carrying capacity continues to increase, more than half of the cities reach a critical loadable state, Kunming first entered the state of loading; the third stage is 2013-2016. In the year, the city's comprehensive carrying capacity continued to increase, and all cities entered a critically loadable or loaded state. As of 2016, Kunming, Guiyang and Nanning entered the state of loading in the third stage. Due to multiple factors such as climate and geomorphology, location conditions, development basis, regional policies, and human capital, the southwestern ethnic region have led to the relative backwardness of the development of the southwestern ethnic region. However, over the years, the state has continuously increased its finance, education, medical care, and public services to the southwestern ethnic region. The investment in the area has enabled the region to continue to develop and the

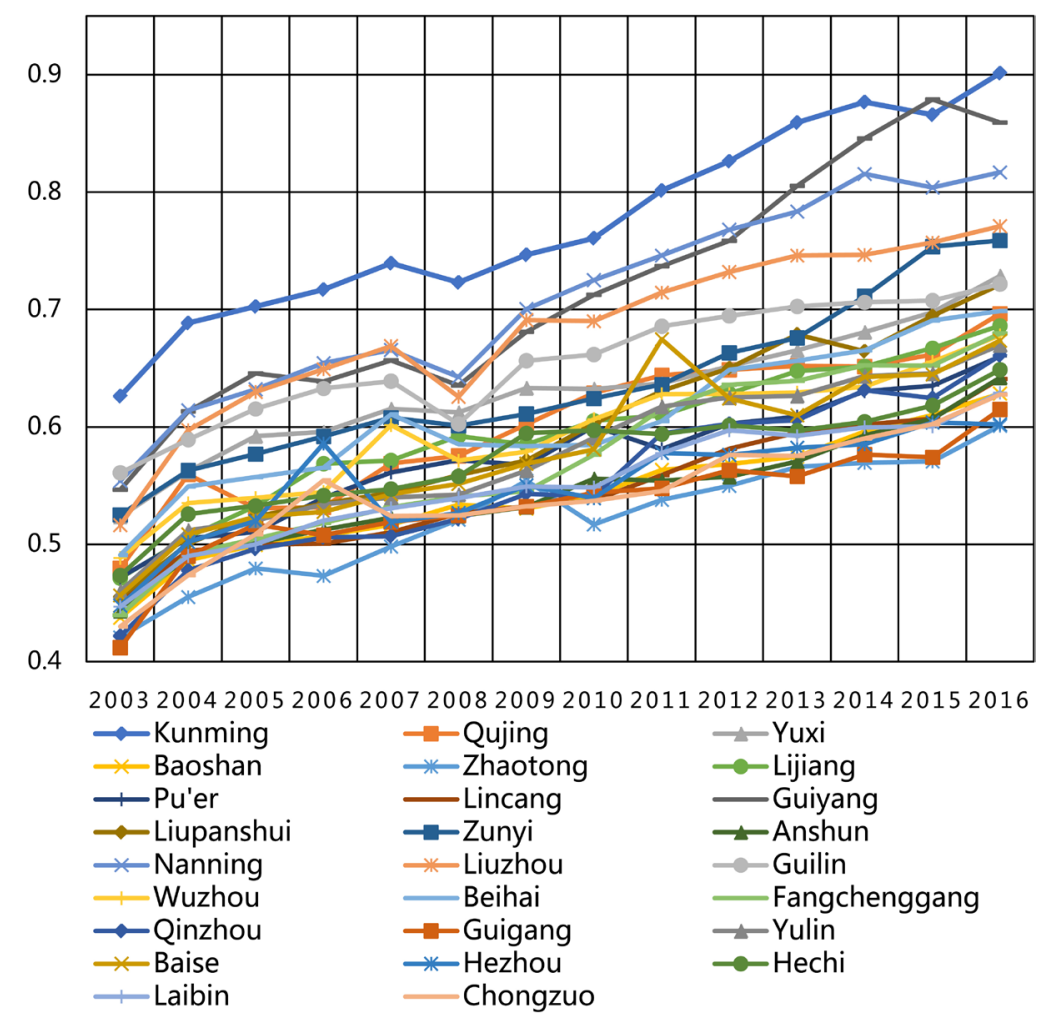

Figure 1. Changes in the comprehensive carrying capacity of cities in the southwest ethnic regions from 2003 to 2016. 
comprehensive carrying capacity of the city has continued to increase. In 2008, affected by the international financial environment, the domestic situation is not optimistic. Therefore, the comprehensive carrying capacity of some cities in the southwestern ethnic region has also been affected by certain impacts, especially in cities with relatively good financial development such as Kunming, Guiyang and Nanning, where the financial industry developed relatively well, the impact was even greater, and economic development was greatly affected, resulting in a decline in the city's comprehensive carrying capacity. After the financial crisis, the state introduced some large-scale construction projects and relaxed monetary and other policies. After the " $18^{\text {th }}$ National Congress", China further optimized the industrial structure and promoted industrial upgrading, which provided a good development environment for the improvement of urban carrying capacity. The urban carrying capacity of the southwestern ethnic region has been significantly improved.

In order to further understand the spatial differences of the comprehensive carrying capacity of cities and the grading characteristics of the comprehensive carrying capacity of each city, this paper selects the comprehensive carrying capacity of cities in 2003 and 2016 for comparative analysis. The R-language software is used to systematically cluster the urban comprehensive carrying capacity of 26 cities in southwestern ethnic region. According to the clustering results, the southwestern ethnic region is divided into three categories, which in turn represent the population characteristics of the city's comprehensive carrying capacity from large to small (Table 5).

Table 5 shows that there were 7 cities in the first and second category carrying capacity in 2003, of which only one city was in the first category carrying capacity, namely Kunming; In 2016, there were 8 cities in the first and second category carrying capacity, of which 3 were in the first category carrying capacity, namely Kunming, Guiyang and Nanning, These three cities are capital cities of the southwestern ethnic region, and the level of urban development is relatively high. Compared with the city with the third category carrying capacity, the city with the second category carrying capacity has a relatively high level of urban development. This shows that in the southwestern ethnic region, the level of urban

Table 5. Classification characteristics of comprehensive carrying capacity of each city.

\begin{tabular}{|c|c|c|}
\hline Level & 2003 & 2016 \\
\hline First category & Kunming (1) & Kunming, Guiyang, Nanning (3) \\
\hline Second category & $\begin{array}{l}\text { Liuzhou, Yuxi, Zunyi, Guiyang, Nanning, } \\
\text { Guilin (6) }\end{array}$ & $\begin{array}{l}\text { Yuxi, Liupanshui, Guilin, Zunyi, } \\
\text { Liuzhou (5) }\end{array}$ \\
\hline Third category & $\begin{array}{l}\text { Wuhzou, Beihai, Qujing, Hechi, Lijiang, } \\
\text { Puer, Guigang, Zhaotong, Qinzhou, } \\
\text { Chongzuo, Baoshan, Fangchenggang, } \\
\text { Yulin, Liupanshui, Baise, Lincang, Anshun, } \\
\text { Hezhou, Laibin (19) }\end{array}$ & $\begin{array}{l}\text { Qujing, Beihai, Puer, Qinzhou, } \\
\text { Lijiang, Wuhzou, Fangchenggang, } \\
\text { Yulin, Baise, Guigang, Zhaotong, } \\
\text { Hezhou, Laibin, Baoshan, Chongzuo, } \\
\text { Hechi, Lincang, Anshun (18) }\end{array}$ \\
\hline
\end{tabular}


comprehensive carrying capacity is directly related to the level of urban development. Cities with higher levels of urban development have relatively high economic levels and usually have better education, medical care, public services, infrastructure and other resources, therefore they have higher carrying capacity in economy, public service and transportation than other cities.

\subsection{Development of Carrying Capacity of Each Element}

In order to better understand the development of urban element carrying capacity in southwestern ethnic region and to analyze the development trend of the carrying capacity of each element and the magnitude of the changes of each element, this paper calculates the annual average of the carrying capacity of each element in 26 cities in 2003-2016 (Figure 2) and the changes carrying capacity of each city in 2003 and 2016 (Figure 3).

From the overall perspective of Figure 2, urban resources and traffic \& communication capacity are relatively high, economic and public service carrying capacity is second, and population and environmental carrying capacity levels are relatively low. From 2003 to 2016, the urban population carrying capacity showed a downward trend. The population carrying capacity of each city varied from $-3.06 \%$ to $0.63 \%$. This shows that in the process of development of the city, a large number of people flock to the city, increasing the pressure on the city to accommodate the population, and resulting in a decline in the population carrying capacity of each city. From 2003 to 2016, the urban environmental carrying capacity increased by a small amount, and the environmental carrying capacity of each city varied from $-1.04 \%$ to $7.37 \%$, with a large range of changes. In recent years, with the country's emphasis on environmental protection, various environmental protection policies have been introduced. The cities actively responded to national policies, strengthened urban city appearance and environmental

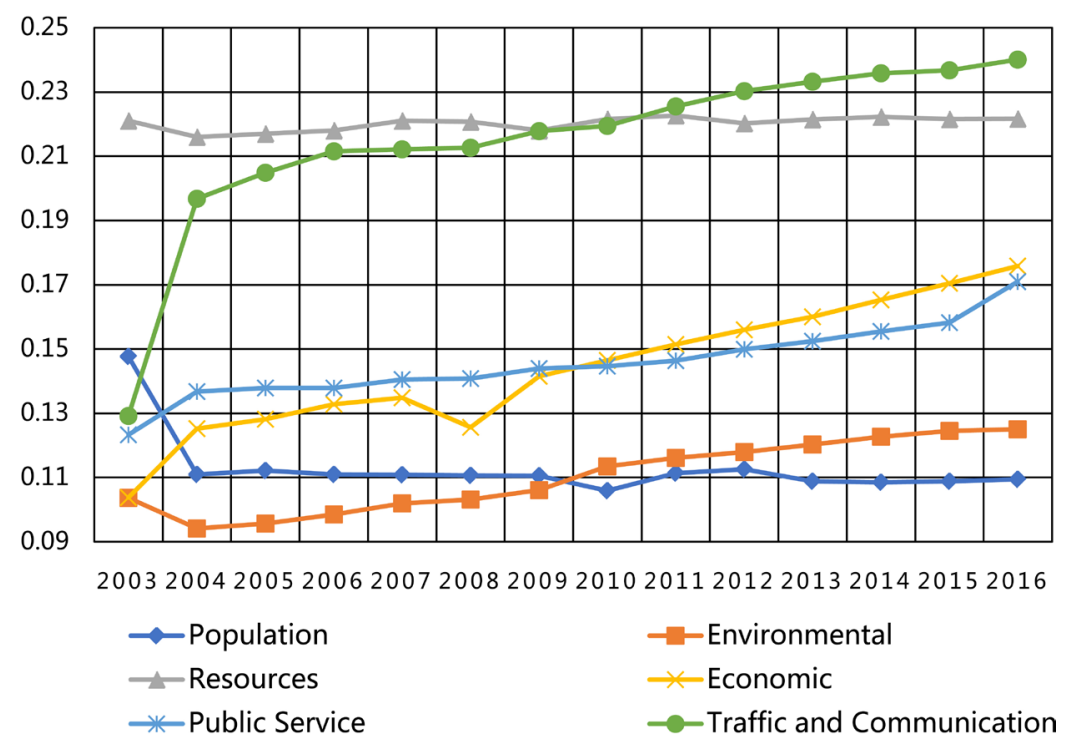

Figure 2. Average development of carrying capacity in southwest ethnic region in 2003-2016. 


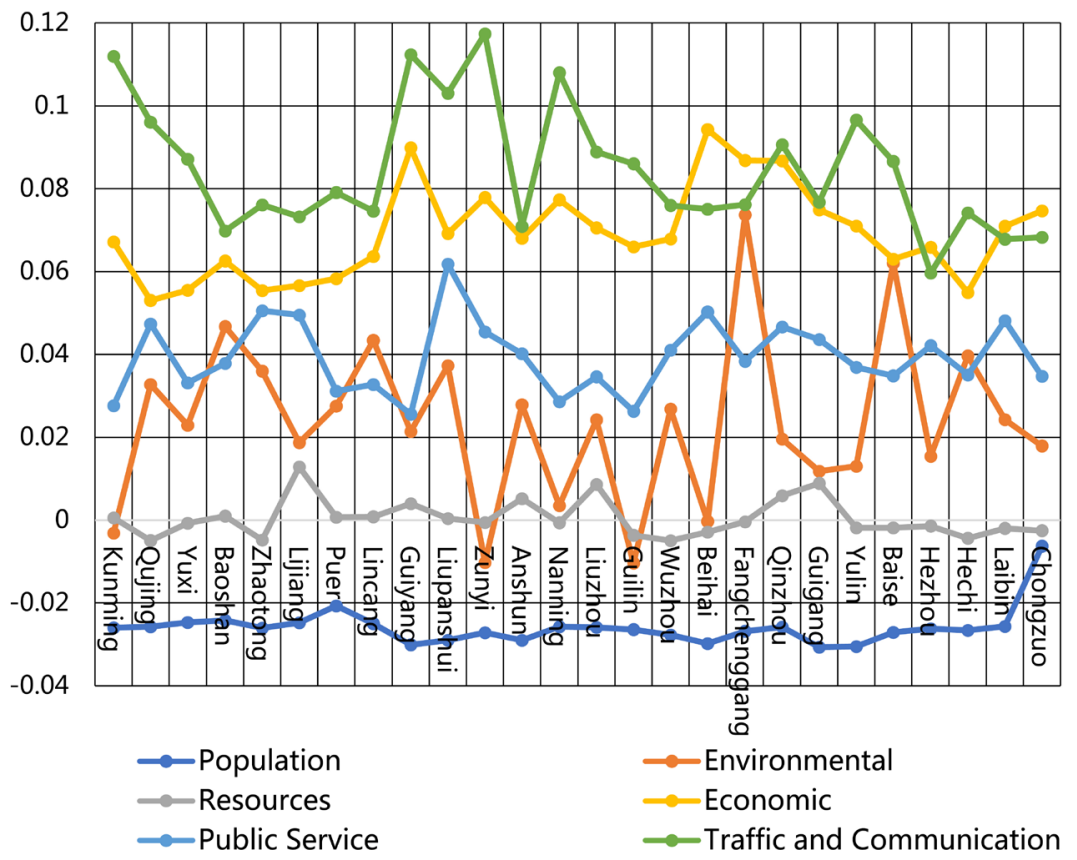

Figure 3. Changes in the carrying capacity of urban elements in the southwestern ethnic region from 2003 to 2016 .

sanitation management, and created clean and beautiful urban work and living environment, which made the urban environmental carrying capacity continuously improved. From 2003 to 2016, the urban resource and environmental carrying capacity showed a trend of declining volatility. The resource carrying capacity of each city varied from $-0.50 \%$ to $1.29 \%$, with a small change range. This shows that although the overall resource carrying capacity of the southwestern ethnic region is relatively high, the cities still face severe trends such as energy shortages and resource shortages in the development process. From 2003 to 2016, the urban economic carrying capacity showed an upward trend, and the economic carrying capacity of each city ranged from $5.30 \%$ to $9.42 \%$, with a large range of changes. This shows that the economic growth of cities in the southwestern ethnic region and the development of the tertiary industry have promoted economic transformation and industrial structure, so the economic carrying capacity of each city has been improved. From 2003 to 2016, the urban public service carrying capacity showed an upward trend. The change of public service carrying capacity in each city ranged from $2.55 \%$ to $6.18 \%$, with a large range of changes. This indicates that in recent years, cities have gradually increased their attention to public services. The financial expenditures in education and medical care are increasing, so the carrying capacity of public services is constantly increasing. From 2003 to 2016, the carrying capacity of urban traffic \& communications continued to rise, and the range of traffic \& communications carrying capacity in each city ranged from $5.96 \%$ to $11.74 \%$, with a large range of changes. This shows that within 14 years, the cities have developed rapidly in transportation and communication, the transportation infrastructure has been 
improved, and the communication infrastructure construction capacity has been continuously enhanced. Therefore, the urban transportation communication capacity has been significantly improved.

Using the coupling coordination degree model, this paper measures the coupling coordination degree of urban comprehensive carrying capacity level in southwestern ethnic region in 2003-2016. The results are shown in Table 6. It can be seen from Table 6 that the coupling coordination level of the comprehensive carrying capacity of most cities has increased, but the degree of coupling

Table 6. Coupling coordination degree of urban comprehensive carrying capacity in southwest ethnic region.

\begin{tabular}{|c|c|c|c|c|c|c|}
\hline City & $2003 \mathrm{D}$ & $\begin{array}{c}\text { Coupling } \\
\text { coordination } \\
\text { level }\end{array}$ & $\begin{array}{c}\text { Carrying } \\
\text { capacity } \\
\text { status }\end{array}$ & $2016 \mathrm{D}$ & $\begin{array}{c}\text { Coupling } \\
\text { coordination } \\
\text { level }\end{array}$ & $\begin{array}{c}\text { Carrying } \\
\text { capacity } \\
\text { status }\end{array}$ \\
\hline Kunming & 0.667 & $\mathrm{D}_{7}$ & $\mathrm{~S}_{3}$ & 0.716 & $\mathrm{D}_{8}$ & $\mathrm{~S}_{4}$ \\
\hline Qujing & 0.462 & $\mathrm{D}_{5}$ & $\mathrm{~S}_{2}$ & 0.459 & $\mathrm{D}_{5}$ & $\mathrm{~S}_{3}$ \\
\hline Yuxi & 0.521 & $\mathrm{D}_{6}$ & $\mathrm{~S}_{2}$ & 0.574 & $\mathrm{D}_{6}$ & $\mathrm{~S}_{3}$ \\
\hline Baoshan & 0.296 & $\mathrm{D}_{3}$ & $\mathrm{~S}_{2}$ & 0.326 & $\mathrm{D}_{4}$ & $\mathrm{~S}_{3}$ \\
\hline Zhaotong & 0.183 & $\mathrm{D}_{2}$ & $\mathrm{~S}_{2}$ & 0.196 & $\mathrm{D}_{2}$ & $\mathrm{~S}_{3}$ \\
\hline Lijiang & 0.474 & $\mathrm{D}_{5}$ & $\mathrm{~S}_{2}$ & 0.481 & $\mathrm{D}_{5}$ & $\mathrm{~S}_{3}$ \\
\hline Puer & 0.446 & $\mathrm{D}_{5}$ & $\mathrm{~S}_{2}$ & 0.409 & $\mathrm{D}_{5}$ & $\mathrm{~S}_{3}$ \\
\hline lincang & 0.334 & $\mathrm{D}_{4}$ & $\mathrm{~S}_{2}$ & 0.395 & $\mathrm{D}_{4}$ & $\mathrm{~S}_{3}$ \\
\hline Guiyang & 0.561 & $\mathrm{D}_{6}$ & $\mathrm{~S}_{2}$ & 0.686 & $\mathrm{D}_{7}$ & $\mathrm{~S}_{4}$ \\
\hline Liupanshui & 0.415 & $\mathrm{D}_{5}$ & $\mathrm{~S}_{2}$ & 0.513 & $\mathrm{D}_{6}$ & $\mathrm{~S}_{3}$ \\
\hline Zunyi & 0.552 & $\mathrm{D}_{6}$ & $\mathrm{~S}_{2}$ & 0.582 & $\mathrm{D}_{6}$ & $\mathrm{~S}_{3}$ \\
\hline Anshun & 0.383 & $\mathrm{D}_{4}$ & $\mathrm{~S}_{2}$ & 0.349 & $\mathrm{D}_{4}$ & $\mathrm{~S}_{3}$ \\
\hline Nanning & 0.573 & $\mathrm{D}_{6}$ & $\mathrm{~S}_{2}$ & 0.643 & $\mathrm{D}_{7}$ & $\mathrm{~S}_{4}$ \\
\hline Liuzhou & 0.518 & $\mathrm{D}_{6}$ & $\mathrm{~S}_{2}$ & 0.594 & $\mathrm{D}_{6}$ & $\mathrm{~S}_{3}$ \\
\hline Guilin & 0.629 & $\mathrm{D}_{7}$ & $\mathrm{~S}_{2}$ & 0.573 & $\mathrm{D}_{6}$ & $\mathrm{~S}_{3}$ \\
\hline Wuzhou & 0.482 & $\mathrm{D}_{5}$ & $\mathrm{~S}_{2}$ & 0.416 & $\mathrm{D}_{5}$ & $\mathrm{~S}_{3}$ \\
\hline Beihai & 0.486 & $\mathrm{D}_{5}$ & $\mathrm{~S}_{2}$ & 0.443 & $\mathrm{D}_{5}$ & $\mathrm{~S}_{3}$ \\
\hline Fangchenggang & 0.216 & $\mathrm{D}_{3}$ & $\mathrm{~S}_{2}$ & 0.421 & $\mathrm{D}_{5}$ & $\mathrm{~S}_{3}$ \\
\hline Qinzhou & 0.264 & $\mathrm{D}_{3}$ & $\mathrm{~S}_{2}$ & 0.405 & $\mathrm{D}_{5}$ & $\mathrm{~S}_{3}$ \\
\hline Guiyang & 0.192 & $\mathrm{D}_{2}$ & $\mathrm{~S}_{2}$ & 0.224 & $\mathrm{D}_{3}$ & $\mathrm{~S}_{3}$ \\
\hline Yulin & 0.424 & $\mathrm{D}_{5}$ & $\mathrm{~S}_{2}$ & 0.367 & $\mathrm{D}_{4}$ & $\mathrm{~S}_{3}$ \\
\hline Baise & 0.375 & $\mathrm{D}_{4}$ & $\mathrm{~S}_{2}$ & 0.428 & $\mathrm{D}_{5}$ & $\mathrm{~S}_{3}$ \\
\hline Hezhou & 0.354 & $\mathrm{D}_{4}$ & $\mathrm{~S}_{2}$ & 0.226 & $\mathrm{D}_{3}$ & $\mathrm{~S}_{3}$ \\
\hline Hechi & 0.432 & $\mathrm{D}_{5}$ & $\mathrm{~S}_{2}$ & 0.403 & $\mathrm{D}_{5}$ & $\mathrm{~S}_{3}$ \\
\hline Laibin & 0.322 & $\mathrm{D}_{4}$ & $\mathrm{~S}_{2}$ & 0.325 & $\mathrm{D}_{4}$ & $\mathrm{~S}_{3}$ \\
\hline Chongzuo & 0.229 & $\mathrm{D}_{3}$ & $\mathrm{~S}_{2}$ & 0.256 & $\mathrm{D}_{3}$ & $\mathrm{~S}_{3}$ \\
\hline
\end{tabular}


coordination is still low. In 2003, the city with the highest degree of coupling coordination was Kunming, and the lowest was Zhaotong. By 2016, Kunming increased from 0.667 to 0.716 , from the primary coordination level to the intermediate coordination level, while Zhaotong increased from 0.183 to 0.196 . The coupling coordination level is still at a severely disordered level. Overall, these cities (Qujing, Lijiang, Puer, Wuzhou, Beihai, Hechi), have been on the verge of being out of tune for 14 years. The cities that have risen by one grade include Baoshan, Guiyang, Liupanshui, Nanning, Guigang, and Baise. The cities that rise in two grades are Fangchenggang and Qinzhou, and the cities that fall one grade include Guilin, Yulin and Hezhou. It can be seen that the number of cities with higher coupling coordination levels is small, and the level of overall coupling coordination level in southwestern ethnic region is relatively low. The close interaction between the six elements of population, environment, resources, economy, public service, and transportation is not high, and there is still much room for improvement in the future.

In addition, it can be seen from the carrying capacity status of each city and the coupling coordination degree of each element that the coupling coordination degree of comprehensive carrying capacity and carrying capacity of cities in southwestern ethnic region has a synchronous development trend. The city has a relatively high carrying capacity and its element coupling coordination degree is also high. Therefore, the degree of coupling coordination between the six elements of the city's comprehensive carrying capacity can be more confirmed. The urban comprehensive carrying capacity of the southwestern ethnic region is directly related to the level of urban development. The urban comprehensive carrying capacity of cities with high urban development level is also high.

\section{Conclusion and Discussion}

By constructing the evaluation index system of urban comprehensive carrying capacity, this paper uses entropy method and coupling coordination degree model to calculate the comprehensive carrying capacity level of each city in the southwestern ethnic region in 2003-2016 and the coupling coordination degree between its elements.

It has been found that the overall carrying capacity of cities in the southwestern ethnic region has shown an upward trend. From the perspective of time series, the comprehensive carrying capacity of cities in the southwestern ethnic region has evolved in the volatility, and the comprehensive carrying capacity level of 26 cities can be divided into three stages: The first stage is from 2003 to 2008 . Most of the cities are overloaded. Only a small number of cities are in a critically loadable state. The second stage is from 2009 to 2012. The urban comprehensive carrying capacity is continuously improved, and more than half of the cities reach the critical point; the third phase was 2013-2016, the city's comprehensive carrying capacity continued to increase, and all cities entered a critically loadable or loaded state. China further optimized the industrial structure and promoted 
industrial upgrading, which provided a good development environment for the improvement of urban carrying capacity. The urban carrying capacity of the southwestern ethnic region has been significantly improved. From 2003 to 2016, the comprehensive carrying capacity of 26 cities in the southwestern ethnic region has been upgraded by one or two levels, and there is still much room for improvement in the future.

Among the carrying capacity of each element, the resource and traffic \& communication carrying capacity are relatively high, the economic and public service carrying capacity level is second, and the population and environmental carrying capacity level are relatively low. From the perspective of the carrying capacity of various cities, the resource and traffic communication capacity are high in 2003-2016, especially the infrastructure such as transportation and communication is continuously improved, the traffic \& communication capacity are greatly improved; the economic and public service carrying capacity is improved to some extent. While population and environmental carrying capacity fluctuate, urban population and environmental development are still facing a very serious situation.

The coupling coordination degree of each element is not high overall, and the comprehensive carrying capacity and element coupling coordination degree of each city in southwestern ethnic region show the spatial and temporal patterns of "double high" and "double low". The comprehensive carrying capacity of a city is affected by various elements, and any part of the elements will determine the carrying level of the city. Therefore, this paper studies the coupling coordination degree of each element of urban comprehensive carrying capacity, and finds that the level of coupling coordination degree of each element is relatively low. This shows that the close interaction between the six elements of population, environment, resources, economy, public service, and traffic \& communication is not high.

From the perspective of space, under the background of the gap between the development of cities in the southwestern ethnic region, the urban comprehensive carrying capacity has evolved into two development patterns: one is the "double high" pattern of "high carrying capacity and high coupling coordination degree", and the other is the "double low" pattern of "low carrying capacity and low coupling coordination degree". From the above, Kunming, Guiyang and Nanning can be classified as "double high", and the remaining cities are classified as "double low". The emergence of these two development patterns is mainly due to the relative lack of resources in the southwestern ethnic region. Capital cities such as Kunming, Guiyang and Nanning usually have a variety of resources that can provide a material basis for the development of the city, so these cities have relatively high carrying levels. Other cities in the southwestern ethnic region have relatively few elemental resources and are not strong in driving urban development. Therefore, the carrying capacity of these cities is relatively low. Due to the lack of element resources, the level of coupling coordination of 
elements is difficult to improve. These two development patterns reflect the current lack of development elements and the contradiction between development elements in the southwestern ethnic region. This is also an objective test for the southwestern ethnic region in the future urban development process.

The urban comprehensive carrying capacity is a complex and systematic concept. This paper selects 26 indicators from the six aspects of population, environment, resources, economy, public service and traffic \& communication to construct an evaluation index system for urban comprehensive carrying capacity, and 26 cities in the southwestern ethnic region were selected as research objects, and the effects of social economy, environmental resources and human activities on the comprehensive carrying capacity of the city were considered comprehensively. At present, there is no clear definition of the comprehensive carrying capacity of cities. This paper believes that the imperfection of urban carrying capacity should be the driving force for further deepening research, and new evaluation methods and models can be explored.

\section{Funding}

This research was funded by the National Social Science Foundation of China (14MXZ060) and the Guangxi Natural Science Foundation Joint Funding and Cultivation Project (2018GXNSFAA294131).

\section{Conflicts of Interest}

The authors declare no conflicts of interest regarding the publication of this paper.

\section{References}

Arrow, K., Bolin, B., Costanza, R., Dasgupta, P., Folke, C. et al. (1995). Economic Growth, Carrying Capacity, and the Environment. Science, 268, 520-521. https://doi.org/10.1126/science.268.5210.520

Catton, W. R. (1987). The World's Most Polymorphic Species: Carrying Capacity Transgressed Two Ways. Bioscience, 37, 413-419. https://doi.org/10.2307/1310565

Chen, J. Y., Yang, Q. S., \& Ma, Z. H. (2013). Evaluation of the Comprehensive Carrying Capacity of Urban Agglomeration in Different Development Stages. Economic Geography, 33, 68-72+85.

Clarke, A. L. (2002). Assessing the Carrying Capacity of the Florida Keys. Population and Environment, 23, 405-418. https://doi.org/10.1023/A:1014576803251

Daly, H. E. (1990). Carrying Capacity as a Tool of Development Policy the Ecuadoran Amazon and Paraguayan Chaco. Ecological Economics, 2, 187-195. https://doi.org/10.1016/0921-8009(90)90030-X

Dhondt, A. A. (1988). Carrying Capacity: A Confusing Concept. Acta Oecologica Oecologia Generalis, 9, 337-346.

Downs, J. A., Gates, R. J., \& Murray, A. T. (2008). Estimating Carrying Capacity for Sandhill Cranes Using Habitat Suitability and Spatial Optimization Models. Ecological Modelling, 214, 284-292. https://doi.org/10.1016/j.ecolmodel.2008.02.006 
Ehrlich, P. R., \& Wilson, E. O. (1991). Biodiversity Studies: Science and Policy. Science, 253, 758-762. https://doi.org/10.1126/science.253.5021.758

Fang, G. X., \& Zhang, H. Y. (2015). The Key Value of "New-Type Urbanization" and Its Path for Cities of Ethnic Areas. Ethno-National Studies, No. 1, 13-24+123-124.

Feng, H. J., \& Yang, H. J. (2013). Sustainable Development of Yulin City and Its Evaluation and Forecast by Pressure-State-Response Model. Bulletin of Soil and Water Conservation, 33, 64-69.

Fu, J. C., Chang, X. H., \& Chen, J. (2014). Spatial-Temporal Variation of Urban Comprehensive Carrying Capacity in West Part of China on the PSR Framework-A Case Study of Xinjiang. Modern Urban Research, No. 8, 56-62.

Gao, H. L., Tu, J. J., \& Yang, L. (2010). Evaluation of the Comprehensive Carrying Capacity of Cities: Take Chengdu-Chongqing Economic Zone as an Example. Journal of Southwest University (Natural Science Edition), 32, 148-152.

Gonzalez-Mejia, A. M., Eason, T., Cabezas, H., \& Suidan, M. T. (2012). Computing and Interpreting Fisher Information as a Metric of Sustainability: Regime Changes in the United States Air Quality. Clean Technologies and Environmental Policy, 14, 775-788. https://doi.org/10.1007/s10098-011-0445-2

Hardin, G. (1976). Carrying Capacity as an Ethical Concept. Soundings: An Interdisciplinary Journal, 59, 120-137.

Hopton, M. E., Cabezas, H. et al. (2010). Development of a Multidisciplinary Approach to Assess Regional Sustainability. International Journal of Sustainable Development, 17, 48-56. https://doi.org/10.1080/13504500903488297

Kozlowski, J. M. (1990). Sustainable Development in Professional Planning: A Potential Contribution of the EIA and UET Concepts. Landscape and Urban Planning, 19, 307-332. https://doi.org/10.1016/0169-2046(90)90040-9

Li, D. X., \& Zhao, H. Q. (2008). A Research on the Structure Model and Mutural Mechanism of Comprehensive Urban Carrying Capacity. Urban Studies, 15, 37-42.

Liu, H. M. (2011). Global Factor Analysis and Spatial Differentiation Study on Comprehensive Carrying Capacity of Urban Agglomeration in the Yangtze River Delta. China Soft Science, No. 10, 114-122.

Liu, Y. B., Li, R. D., \& Song, X. F. (2005). Analysis of Coupling Degrees of Urbanization and Ecological Environment in China. Journal of Natural Resources, 20, 105-112.

Malthus, T. R. (1798). Essay on the Principle of Population. London: J. Johnson, in St. Paul's Churchyard.

Mu, X. Y., Liu, K., \& Ren, J. L. (2017). Spatial Pattern of the Comprehensive Carrying Capacity of Cities at Prefecture Level and above in China under the Background of New Urbanization. Arid Land Geography, 40, 671-679.

Oh, K. (1998). Visual Threshold Carrying Capacity (VTCC) in Urban Landscape Management: A Case Study of Seoul, Korea. Landscape and Urban Planning, 39, 283-294. https://doi.org/10.1016/S0169-2046(97)00085-6

Oh, K., Jeong, Y., Lee, D., Lee, W., \& Choi, J. (2005). Determining Development Density Using the Urban Carrying Capacity Assessment System. Landscape and Urban Planning, 73, 1-15. https://doi.org/10.1016/j.landurbplan.2004.06.002

Randolph, J. (2004). Environmental Land Use Planning and Management. Environmental Land Use Planning\& Management, 24, 172-185.

Robert, P., \& Burgess, E. (1921). Introduction to the Science of Sociology. Chicago, IL: University of Chicago Press. 
Sarma, A. K., Mahanta, C., Bhattacharya, R., Dutta, S., Kartha, S., Kumar, B., \& Sreeja, P. (2012). Urban Carrying Capacity: Concept and Calculation. Assam, India: Centre of Excellence.

Seidl, I., \& Tisdell, C. A. (1999). Carrying Capacity Reconsidered: From Malthus' Population Theory to Cultural Carrying Capacity. Ecological Economics, 31, 395-408. https://doi.org/10.1016/S0921-8009(99)00063-4

Tan, W. K., Shi, Y. H., \& Sun, L. (2008). Some Theoretical Issues on Urban Carrying Capacity. China Population Resources and Environment, 18, 40-44.

Tehrani, N. A., \& Makhdoum, M. F. (2013). Implementing a Spatial Model of Urban Carrying Capacity Load Number (UCCLN) to Monitor the Environmental Loads of Urban Ecosystems. Case Study: Tehran Metropolis. Ecological Indicators, 32, 197-211. https://doi.org/10.1016/j.ecolind.2013.03.022

Verhulst, P. F. (1838). Notice sur la loi que la populaions suit dans son accroissement. Correspondance Mathématique et Physique, 10, 113-121.

Wang, L., Guan, Z. H., Zhang, S. Q., \& Li, M. J. (2018a). Coupling Coordination and Spatial-Temporal Differentiation of Chinese Inclusive Finance. Soft Science, 32, 10-15.

Wang, Z. P., Zhu, D., \& Wang, L. Y. (2018b). The Evaluation of Urban Comprehensive Carrying Capacity of Beijing-Tianjin-Hebei Urban Agglomeration under Regional Collaboration. Journal of Capital University of Economics and Business, 20, 73-81.

Zeng, P., Wang, Y. Q., \& Zhang, X. J. (2015). Comparative Study on the Carrying Capacity of Top Ten Urban Agglomerations in China. Statistics \& Information Forum, 30, 76-82.

Zhu, Y. H., Drake, S., Lü, H. S., \& Xia, J. (2010). Analysis of Temporal and Spatial Differences in Eco-Environmental Carrying Capacity Related to Water in the Haihe River Basins, China. Water Resources Management, 24, 1089-1105.

https://doi.org/10.1007/s11269-009-9487-1 